\title{
CLASIFICACIÓN Y ESTUDIO DE LAS PERÍFRASIS VERBALES CON SIGNIFICADO FACTUAL EN LA CARTA A SOR FILOTEA DE LA CRUZ*
}

\author{
PATRICIA FERNÁNDEZ MARTÍN \\ Universidad Autónoma de Madrid
}

RESUMEN: El objetivo de este artículo es describir el uso de las perífrasis verbales factuales empleadas por sor Juana Inés de la Cruz en su Respuesta de la poetisa a la muy ilustre sor Filotea de la Cruz (1691). Para ello, se comienza con algunas cuestiones ecdóticas sobre el texto estudiado y asunciones sobre la perífrasis verbal. A continuación, se ofrecen los datos según los auxiliares sean verbos de movimiento o las construcciones expresen gradación, cuantificación o pasividad. La interpretación de los datos lingüísticos permite concluir con la posibilidad de que la carta tenga forma de autobiografía pero se deje imbuir por un contenido claramente ensayístico de tipo filosóficoteológico plasmable en su estructura gramatical.

PALABRAS CLAVE: perífrasis verbales, Sor Juana Inés de la Cruz, autobiografía, Sor Filotea de la Cruz

\section{Classification and study of verbal periphrases with factual meaning in Carta a sor Filotea de la Cruz}

\begin{abstract}
The aim of this article is to describe the use of factual verbal periphrases in sor Juana Inés de la Cruz's Respuesta de la poetisa a la muy ilustre sor Filotea de la Cruz (1691). In the first part we explain some ecdotic questions about this text and some assumptions concerning verbal periphrases. After that, we present the data, taking into account whether the auxiliaries are verbs of movement or the verbal periphrases express gradation, quantification, or passivity. The interpretation of the linguistic data allows us to conclude with the possibility that the letter has the form of an autobiography but its content comes close to a philosophical-theological essay, as seen in the grammatical structure.
\end{abstract}

KEYWORDS: verbal periphrases, Sor Juana Inés de la Cruz, autobiography, Sor Filotea de la Cruz

\section{INTRODUCCIÓN}

Dada la (aún) escasa bibliografía existente dedicada al estudio lingüístico de conjuntos de textos compuestos (exclusivamente) por mujeres a lo largo de la historia de la lengua española - entendiendo por tal lo que se ofrece, por ejemplo, en la serie de trabajos editados por Almeida Cabrejas, Díaz Moreno y Fernández López (2017) - , ${ }^{1}$ puede parecer relevante aplicar a la Respuesta de la poetisa a la muy ilustre sor Filotea de la Cruz (1691), de sor Juana Inés de la Cruz, una serie de parámetros que nos sirvan, por un lado, para conocer más la gramática 
española del Siglo de Oro y, por otro, para profundizar en el estudio (lingüístico) de los escritos de la jerónima mexicana. Estos dos objetivos específicos se insertan en uno más amplio, como es el de incorporar los textos femeninos al estudio de la historia de la lengua que, entendemos, ha de comenzar desde una perspectiva microanalítica (es decir, idiolectal), para poder terminar, llegado el caso, efectuándose desde una perspectiva macroanalítica (diafásica, diastrática, diatópica).

Naturalmente, somos conscientes de las limitaciones que ofrece el método cualitativo que emplearemos aquí, así como de la dificultad que entraña que se pueda profundizar en el estudio lingüístico del texto de sor Juana Inés de la Cruz centrándonos solo en un aspecto muy concreto de la morfosintaxis, como son ciertas perífrasis verbales, seleccionadas, precisamente, por una rica complejidad que afecta a gran parte de la gramática y el léxico de la lengua (Yllera, 1980, 1999; Gómez Torrego, 1988, 1999; Iglesias Bango, 1988; Gómez Manzano, 1992; Veyrat Rigat, 1993; Olbertz, 1998; Fernández de Castro, 1999; García Fernández, 2006; Zieliński, 2014; Fernández Martín, 2014, 2015c, 2016a, 2018, 2019). Sin embargo, consideramos factible el método idiolectal por dos motivos esenciales. El primero se relaciona con una realidad textual, como es el hecho de que no hay realmente posibilidad de estudiar los textos escritos por mujeres desde una perspectiva cuantitativa equiparable a la que se mantiene para analizar los discursos producidos por hombres, dado que la inmensa mayoría de los textos transcritos, codificados y etiquetados pertenecen a varones, por motivos sociohistóricos sobradamente conocidos. Por tanto, hay un sesgo de género que se puede añadir al sesgo habitual que se da en historia de la lengua y afecta a los discursos en general (es decir, lo que [no] nos llega por avatares históricos, por [no] haber sido redactado por clases privilegiadas, hablantes de lenguas dominantes, vencedores de guerras, etc.). Entendemos, pues, que una forma de empezar a pulir dicho sesgo de género es incorporando el discurso de la mujer al análisis lingüístico en profundidad, como se hacía antes de la actual y revolucionaria lingüística de corpus con los discursos escritos (fundamentalmente) por hombres, que eran los que estaban más a mano para los investigadores. $\mathrm{Al}$ fin y al cabo, desde la perspectiva del método idiolectal defendido, por ejemplo, por BarraJover (2012), asumir una manera individual de ver el mundo que pueda o no generalizarse con estudios posteriores es contribuir, aunque sea con un minúsculo granito de arena, al conocimiento del funcionamiento de la lengua en determinado momento de su historia.

Esta posibilidad de defender el idiolecto como primer paso del camino a un conocimiento más profundo del sistema lingüístico de toda una comunidad nos lleva al segundo motivo por el que resulta metodológicamente aceptable generalizar lo particular, como se hace en algunos momentos del presente trabajo (quizá más de lo deseado): la regla de introducción del cuantificador universal establecida por la lógica formal aristotélica. En efecto, la lógica acepta como válido un argumento en el que se pasa de una afirmación centrada en un individuo a una afirmación relativa a todos los individuos de un cierto conjunto (Deaño, 2009, 276-282). Las razones son dos. La primera de ellas es que el individuo del que parte dicha regla de deducción natural es un individuo cualquiera. En nuestro caso, el idiolecto de sor Juana Inés de la Cruz es respetable por sí mismo en tanto producto lingüístico efectuado por un hablante nativo en determinado momento sociohistórico $\mathrm{y}$, por ello, de un inestimable valor lingüístico, ${ }^{2}$ independientemente, por supuesto, del incuestionable valor estético, filosófico y literario que ofrezca el mismo idiolecto o, cuanto menos, el mismo texto. La segunda razón es que, en la 
práctica, resulta imposible acceder a todos y cada uno de los hablantes/escritores de una lengua en un momento histórico determinado y en un lugar concreto (especialmente si no se han dado suficientemente a conocer, como sucede en la inmensa mayoría de los discursos producidos por mujeres). Por tanto, lo que defendemos aquí podrá confirmarse o desmentirse más adelante con sucesivos trabajos que contrasten los resultados de este estudio con la realidad lingüística de la época, según se plasme en una amplia diversidad de documentos (escritos o no por mujeres).

Lo que pretendemos es, pues, ofrecer un estudio sistematizado de las principales perífrasis verbales con significado factual que aparecen en el texto de sor Juana Inés de la Cruz. Para ello, se comienza exponiendo algunas cuestiones metodológicas entre las que se encuentran ciertos aspectos de interés ecdótico sobre el texto estudiado y algunas asunciones sobre el concepto de perífrasis verbal ( $\S 2$ ). A continuación, se ofrece el análisis propiamente dicho, que sigue la clasificación de Zieliński (2014), cuando los auxiliares son verbos de movimiento (§ 3.1); la que Fernández de Castro (1999) aplica a las perífrasis factuales, en el resto de los casos, cuando se muestren significados de gradación ( $§ 3.2$ ) o cuantificación ( $§ 3.3$ ); y la de Fernández Martín (2016d, 2019) al tratar la pasividad (§ 3.4). Se emplea como texto principal la edición de Margo Glantz y María Dolores Bravo Arriaga (1994), publicada por la Biblioteca Ayacucho. A pesar de contener algunos posibles errores con respecto a la edición príncipe (moto por motu [780], ablando por hablando [129]), la precisión de cita que permite la numeración de las líneas en esta edición es extraordinariamente útil para ejemplificar los casos morfosintácticos que interesan aquí. Por último, en el apartado 4 se hace una interpretación de los datos, al compararlos con los extraídos de manera similar de otros textos relevantes para la historia de la lengua española y al relacionarlos con la propia esencia del discurso analizado.

\section{CUESTIONES METODOLÓGICAS}

Fechada el 1 de marzo de 1691, la Respuesta a sor Filotea de la Cruz es la respuesta de sor Juana Inés de la Cruz a una carta escrita el 25 de noviembre de 1690 por Manuel Fernández de Santa Cruz, obispo de Puebla, bajo el pseudónimo de sor Filotea de la Cruz. Dicho texto aparece añadido a la Carta atenagórica de la religiosa, cuya publicación probablemente ella no autorizó (Brescia, 1998, 78; Poot Herrera, 2008, 154). En su carta, el obispo propone a la jerónima alejarse del conocimiento profano y centrarse en el religioso (Salazar Mallén, 1978, 67), dada la supuesta osadía de la mexicana al enjuiciar en la mencionada Carta atenagórica el sermón pronunciado por el teólogo portugués Antonio de Vieyra en 1650 en Lisboa (Brescia, 1998, 78; Poot Herrera, 2008, 154).

Publicada por primera vez en Madrid en 1700, dentro del tomo tercero de Fama y Obras posthumas (Knowlton, 1981, 331; Poot Herrera, 2008, 151), la Respuesta toma la forma de un discurso epistolar que, camuflado en una autobiografía, supone, sin embargo, una defensa argumentada del espacio femenino en el lenguaje culto de la teología. Nuestra intención es, pues, comprobar cómo se plasma esta interacción de textualidades en las estructuras morfosintácticas seleccionadas. Estas son, como se ha dicho, las perífrasis verbales factuales. Debido a lo complejo que resulta definirlas (Gómez Torrego, 1988, 1999; Iglesias Bango, 1988; Fernández de Castro, 1999; Gómez Manzano, 1992; García Fernández, 2006), asumimos la propuesta de Hella 
Olbertz (1998), para quien una perífrasis es la "combinación indisoluble y productiva, por un lado, de un verbo conjugado que funciona como auxiliar $y$, por otro lado, de un verbo en forma no personal, [...] donde el verbo conjugado concuerda morfológicamente con el rol semántico de agente" exigido por el verbo en forma no conjugada, en un proceso que es gradualmente interactivo (Fernández Martín 2014, 2015b, 2015c). Esta interacción se percibe, especialmente, con las perífrasis de verbos de movimiento que son, al fin y al cabo, las que ejemplifican de una manera más transparente el proceso de gramaticalización (Heine, 1992, 2003; Garachana, 2010, 2011a, 2011b), como demuestra, de hecho, la clasificación de Zieliński (2014) empleada aquí, por ofrecer una visión holística del proceso diacrónico de creación de las perífrasis y, a la vez, permitir comprender la convivencia de ejemplos con mayor o menor grado de fusión en los distintos estadios sincrónicos de la lengua.

El resto de las perífrasis verbales de infinitivo y de gerundio registradas en el texto sigue la clasificación de Fernández de Castro (1999). Esta clasificación, aunque utilizada para el español actual, se presta a la perfección a su empleo en otras etapas históricas de la lengua debido, por un lado, al mantenimiento estructural de la perífrasis que existe a lo largo de los siglos; y, por otro, a la flexibilidad conceptual que permite la propuesta de dicho autor.

\section{AlgunAS PERÍFrasis VERBALES FACTUALES DEL TEXTO}

A continuación, efectuamos el análisis de las principales perífrasis verbales factuales localizadas en la Carta a sor Filotea de la Cruz. Las hemos dividido en cuatro grupos, en función de las que existen de facto en dicho texto: las perífrasis formadas con verbos de movimiento ( $\S$ 3.1); las perífrasis que expresan gradación como son empezar a + infinitivo, dejar de + infinitivo y estar + gerundio ( $\S 3.2$ ); la única perífrasis que expresa cuantificación, esto es, soler + infinitivo ( $\S 3.3$ ), y las perífrasis con valores pasivos ( $\S 3.4$ ), que solo pueden considerarse perifrásticas desde una perspectiva histórica (Fernández Martín, 2016d, 2019).

\subsection{Perífrasis factuales con verbos de movimiento}

La presentación de las perífrasis de la Carta a sor Fílotea de la Cruz cuyos verbos auxiliares son considerados tradicionalmente verbos de movimiento va a seguir, como se ha dicho, la clasificación propuesta por Zieliński (2014). Dicha agrupación se basa en el grado de gramaticalización de cada estructura, la cual a su vez viene determinada por varios factores como la selección del sujeto, la intercalación de elementos ajenos (en especial, clíticos), la posibilidad de invertir el orden sintáctico de la construcción y el valor semántico del conjunto de la estructura. Esta interrelación de elementos daría lugar a un grupo de construcciones en vías de evolución (grupo D, en la terminología del autor), otras denominadas semiperífrasis superfluas (grupo C), otras que serían las semiperífrasis fuertes (grupo B) y, por último, las perífrasis altamente gramaticalizadas (grupo A).

Comencemos, pues, con las construcciones en vías de evolución, es decir, las que parecen perifrásticas (pues están conformadas por la estructura \{verbo de movimiento + [nexo + ] forma no personal\}) pero no lo son. Tal es el caso de "que en este supremo auge de la gloria y felicidad humana fuese un soldado, en voz alta diciendo al vencedor, como con sentimiento suyo y orden 
del Senado" (1338-1341), donde la forma pronominal del verbo de movimiento (irse) bloquea (o, al menos, dificulta) cualquier interpretación conjunta, de manera semejante a lo que ocurre en el siguiente ejemplo, en que el mismo contexto espacial determina la imposibilidad de una lectura perifrástica de llegar a + infinitivo: "yo me llegaba a contemplar las figuras que formaban" (790-791).

El fragmento que exponemos a continuación es mucho más complejo:

[...] pero ya desengañados y enterados de que va a dar vida a Lázaro, ¿̇cuál es la razón que pudo mover a Tomás para que tomando aquí los alientos que en el Huerto Pedro: Eamus et nos, ut moriamur cum eo [?] ¿Qué dices, apóstol santo? A morir no va el Señor, ¿̇de qué es el recelo? Porque a lo que Cristo va no es a reprender, sino a hacer una obra de piedad, y por esto no le pueden hacer mal. (686-693)

En efecto, dejando de lado el valor de permiso natural de pudo mover y de prohibición externa natural de no le pueden hacer mal (Fernández Martín, 2015d), este fragmento resulta altamente llamativo debido a varios motivos. En primer lugar, enterados de que va a dar vida a Lázaro puede interpretarse, sin contexto, como perifrástico, si bien entendemos que el contexto espacial en que se describe el desplazamiento del sujeto, Jesús, que realmente se acerca (se mueve) hacia Lázaro, permite una aproximación, quizá más fiable, hacia la interpretación no perifrástica. En segundo lugar, se da una doble aparición de la construcción en una especie de par adyacente autodialógico, en el que la autora del texto propone una pregunta que ella misma responde. Y, por último, son igualmente reseñables los dos hipérbatos que resultan sumamente clarificadores para establecer la naturaleza estructural de los ejemplos. El primero, a morir no va el Señor, contiene en líneas previas una referencia espacial que hace alusión a la resurrección de Lázaro, lo que supone una posible lectura final de a morir, aunque, como en el caso anterior de va a dar vida a Lázaro, puede entenderse como perifrástico fuera de contexto, si se interpreta que ya no existe ningún significado de movimiento en el verbo ir porque la construcción aluda a la intención de realizar un hecho prácticamente inevitable y, por tanto, se encuentre cerca del valor de obligación. El segundo, a lo que Cristo va no es a reprender, responde igualmente a una estructura disjunta, pues constituye un valiosísimo ejemplo de que la prueba de la focalización por estructura ecuacional -aducida para el español actual, entre otros, por Fernández de Castro (1999, 35) - solo funciona con casos no perifrásticos, lo que necesariamente obliga a una interpretación (en el fondo, de todo el párrafo) en la que el destino del verbo ir se concibe como un espacio físico (el lugar en que se encuentra Lázaro) que complementa el significado final del sintagma introducido por la preposición $a$, primero negado (no va para reprender) y luego afirmado (sino para hacer una obra de piedad). Nótese que, inmediatamente antes de dichas líneas, la misma autora vuelve a dar muestras de una típica prueba de sustitución del infinitivo por un sintagma nominal que confirma su naturaleza no perifrástica (Fernández de Castro, 1999; Olbertz, 1998), como en "Y así temían que si iba a lo mismo [...] corriese peligro su vida" (683-685).

Para contribuir a defender esta lectura no perifrástica de todo el párrafo, la frase que abre la idea de la resurrección de Lázaro parece solo poder entenderse en clave espacial, pues el 
infinitivo dependiente del verbo querer difícilmente se presta al significado intencional (puede resultar semánticamente complejo asumir el deseo de una intención), lo que bloquea el significado perifrástico. Además, el complemento directo de dar (vida) evita una interpretación próxima a la locución de ir a parar (García-Page Sánchez, 2008, 136; Fernández Martín, 2015b): "Quiso la misma Vida ir a dar vida a Lázaro difunto" (676-677).

El segundo grupo de estructuras que estudiamos aquí lo componen las semiperífrasis superfluas, apenas distinguibles de las semiperífrasis fuertes, sobre todo desde una perspectiva estrictamente sincrónica (Yllera, 1980, 1999; Gómez Torrego, 1988, 1999; Fernández de Castro, 1999; Melis, 2006; Garachana, 2010, 2011a, 2011b; Olbertz, 1998; Zieliński, 2014). Debido a esta dificultad, hemos seleccionado un factor que entendemos clave para distinguir entre las semiperífrasis fuertes y las superfluas atendiendo en exclusiva a las características lingüísticas de un texto clásico, en el que la inclusión de clíticos (que podría ser otro factor determinante) puede ser confusa para efectuar esa distinción, por cuestiones que afectan al resto del sistema lingüístico (Girón Alconchel, 2005b; Zieliński, 2014; Fernández de Castro, 1999; Gómez Torrego, 1988, 1999). Dicho elemento clave es el rol semántico del agente, es decir, el valor del sujeto exigido siempre por el auxiliado, pues de otro modo el ejemplo en cuestión pertenecería al grupo de las construcciones perifrásticas en potencia. Así, si tiene significado [+ animado], la construcción será considerada semiperífrasis superflua y no fuerte, porque se entiende que aún queda, siquiera metafóricamente, un resquicio de valor de desplazamiento en el verbo conjugado (Veyrat Rigat, 1993; Garachana, 2010, 2011b):

Pues si ellos dicen que no le quieren apedrear por las buenas obras y ahora va a hacer una tan buena como dar la vida a Lázaro, ¿de qué es el recelo o por qué? ¿No fuera mejor decir: Vamos a gozar el fruto del agradecimiento de la buena obra que va a hacer nuestro Maestro; a verle aplaudir y rendir gracias al beneficio; a ver las admiraciones que hacen del milagro? (698-704)

En efecto, en este ejemplo la interpretación no perifrástica tiene cabida si se entiende todavía dentro del significado de desplazamiento que existe en la concepción que la autora muestra de la resurrección de Lázaro, como demuestra el hecho de que aparezcan los infinitivos a verle aplaudir y a ver las admiraciones - asumidos como objetivos espaciales metafóricos- a una distancia considerable del verbo vamos, del que dependen jerárquicamente. Y, al contrario, también puede aplicarse un valor perifrástico si se entiende como una clara intención o como la descripción de un futuro inminente y, dentro de la concepción del mundo de sor Juana Inés, inevitable, pues es algo ya ocurrido en el pasado y, por tanto, imposible de modificar. Desde esta perspectiva, se encontraría muy cerca del valor modal de obligación interna que a veces tienen algunas perífrasis no factuales como haber de + infinitivo (Fernández Martín, 2015d).

La incursión de los ejemplos "y viendo que acaso se pusieron tres [alfileres] en triángulo, me ponía a enlazar uno en otro" (791-792) y "en la Iglesia primitiva se ponían las mujeres a enseñar las doctrinas unas a otras en los templos" (1056-1058) entre las estructuras con verbos de movimiento, únicos localizados con la perífrasis aspectual incoativa ponerse $a+$ infinitivo, tiene su razón de ser en el valor originario de movimiento que tiene el verbo poner(se). La peculiaridad de este verbo es que es transitivo y necesita al pronombre se para implicar un proceso de desplazamiento como el resto de los verbos de movimiento (ir, venir, andar, volver), 
y no una acción de locomoción, en el sentido de Moreno Cabrera (2003). Queda patente, pues, el contraste, en la esfera sociocognitiva del espacio físico, entre los ejemplos anteriores de enlazar o enseñar y el caso "Cierto, Señora mía, que algunas veces me pongo a considerar" (527-528), más cerca de la semiperífrasis fuerte por el significado mental del verbo en infinitivo.

En el mismo grupo de las semiperífrasis superfluas insertamos todos los ejemplos localizados con la perífrasis de cuantificación reiterativa (Fernández de Castro, 1999) o de modo de acción iterativa (García Fernández, 2006) volver a + infinitivo (de tornar no se ha registrado ningún caso):

y este voto (conociendo mi fragilidad) le hacía por un mes o por quince días; y dando cuando se cumplía, un día o dos de treguas, lo volvía a renovar, sirviendo este día, no tanto a mi descanso (pues nunca lo ha sido para mí el no estudiar), cuanto a que no me tuviesen por áspera, retirada e ingrata al no merecido cariño de mis carísimas hermanas. (490-496)

En el ejemplo anterior y en el siguiente el significado de la perífrasis volver $a+$ infinitivo se encuentra, a nuestro juicio, entre el de restauración y el de repetición: "si cuando volviese a crecer hasta allí no sabía tal o cual cosa que me había propuesto deprender en tanto que crecía, me lo había de volver a cortar en pena de la rudeza" (260-263). Así, el hecho de que crezca el pelo puede implicar tanto la repetición de la acción misma de crecer como la vuelta al estado de tener un cabello más largo que el que se tiene en el momento de la enunciación, igual que sucede con la acción de renovar los votos, pues se entiende que no es la primera vez que se hace y, por tanto, se restaura (a la vez que se repite) el estado de contar con los votos renovados. Con había de volver a cortar, sin embargo, la exclusiva interpretación de restablecimiento de la situación es más compleja, quizá por la naturaleza puntual del evento indicado por el infinitivo y, por tanto, la dificultad de concebirlo como un estado que pueda durar en el tiempo lo suficiente como para que pueda ser restaurado.

El tercer grupo de perífrasis, el de las semiperífrasis fuertes, es el compuesto por aquellos ejemplos cuyo papel semántico de agente exigido por el auxiliado ofrezca un significado [-animado]. El motivo de esta decisión sigue la línea de lo indicado por Zieliński $(2014,47)$, para quien el rol del agente es esencial también en la caracterización del verbo auxiliado como impersonal, defectivo o meteorológico, como se ve en los ejemplos "lo cual se excusara si hubiera ancianas doctas, como quiere San Pablo, y de unas en otras fuese sucediendo el magisterio" (1029-1031) y "hallé que no eran sino unas líneas espirales que iban perdiendo lo circular cuando se iba remitiendo el impulso" (786-788). En estas oraciones, la posibilidad de una interpretación espacial del verbo ir es prácticamente nula, pues no se puede entender el desplazamiento del magisterio y las líneas espirales más que desde una perspectiva totalmente metaforizada, lo que implica un muy alto grado de gramaticalización (Garachana, 2011b; Zieliński, 2014).

De forma similar, no puede desprenderse un valor espacial de los significados de los agentes las líneas visuales o las otras cosillas, en el caso de ir a + infinitivo, que muestra valor de futuro inminente, casi pleonástico: "de donde infería que las líneas visuales corren rectas, pero no paralelas, sino que van a formar una figura piramidal" (764-766); "Si algunas otras cosillas escribiere, siempre irán a buscar el sagrado de vuestras plantas y el seguro de vuestra 
corrección" (1406-1408). No obstante, hay algunas diferencias con respecto a la mencionada perífrasis en gerundio. Así, el primero de estos dos ejemplos (van a formar) no solo se inserta en las semiperífrasis fuertes por el carácter [-animado] del sujeto, sino que, además, puede llegar a considerarse próximo a una construcción altamente gramaticalizada, dado el valor casi fraseológico de la construcción ir a + infinitivo con ciertos verbos, cuya fusión implica un significado 'acabar en' semejante al de ir a parar o ir a dar (Fernández Martín, 2015b).

El interés de la segunda oración (irán a buscar) radica, por su parte, en la forma de futuro del verbo ir, pues expresa un grado muy alto de certeza que podría contrastar con la visión cautelosa y siempre dependiente de los designios de Dios que caracteriza el pensamiento de sor Juana Inés. Asimismo, al emplear una perífrasis que permite una interpretación intencional de la realización del hecho denotado por el infinitivo, se personifica al agente más reificado del idioma, otras cosillas, lo que a su vez impide por completo una interpretación meramente espacial de la construcción, pues esta se encuentra ya excesivamente metaforizada.

Por lo que respecta a "Lo que sí es de ponderar es el trabajo que le ha costado el andar haciendo traslados" (1310-1311), puede justificarse un mayor grado de gramaticalización en la estructura andar haciendo que en la semiperífrasis superflua. Ello se debe a la posibilidad de nominalizar el infinitivo $\mathrm{y}$, por tanto, de convertir a todo el conjunto en una unidad complementada por el artículo.

Dentro del cuarto grupo no podemos incluir ningún ejemplo más allá de algunas pinceladas esbozadas anteriormente. No hemos encontrado en la Carta a sor Filotea de la Cruz ningún extracto, con verbos de movimiento, que supere con claridad ese punto intermedio entre la gramática y el léxico, como puede suceder en otros casos como la formación de los tiempos verbales (gramática), las locuciones verbales (léxico) o los marcadores discursivos (discurso) (Yllera, 1999; García Martín, 2002; Romani, 2006; Girón Alconchel, 2007; Fernández Martín, 2014, 2015b, 2016a).

En síntesis, las construcciones más frecuentes son las semiperífrasis superfluas formadas por volver $a+$ infinitivo, ir $a+$ infinitivo y ponerse $a+$ infinitivo, de las que algunas pueden considerarse, como se ha dicho, semiperífrasis fuertes. Dentro de este grupo, además, se encuentran las más frecuentes, formadas por ir + gerundio e ir a + infinitivo, mientras que de las demás los ejemplos son cuantitativamente escasos, aunque no por ello menos representativos de la lengua hablada a finales del siglo XVII.

\subsection{Perífrasis factuales de gradación}

La perífrasis aspectual incoativa (García Fernández, 2006) o de gradación ingresiva (Fernández de Castro, 1999) empezar a + infinitivo ofrece cinco ejemplos en la Respuesta, de los cuales tres se encuentran en primera persona del singular y en pretérito indefinido. En "y apenas yo vi el movimiento y la figura, cuando empecé, con esta mi locura, a considerar el fácil moto de la forma esférica” (778-780), puede resultar interesante la intercalación de un sintagma preposicional (con esta mi locura) entre el auxiliar y la preposición a, pues esta posibilidad implica un grado de gramaticalización menor del esperado con otras perífrasis, en las que resulta totalmente imposible introducir un constituyente oracional entre el auxiliar y el auxiliado (Heine, 1992, 2003; Girón Alconchel, 2004, 2005a, 2007). 
Los otros dos ejemplos con empezar $a$ + infinitivo aparecen en tercera persona del singular, tanto en el pretérito indefinido como en el pretérito imperfecto: "el que empezó a hacer beneficios se obligó a continuarlos" (1409-1410); "Pues si así quería el Santo que se educase una niña que apenas empezaba a hablar, ¿qué querrá en sus monjas y en sus hijas espirituales?" (1003-1005). No cabe, pues, sorprenderse, de que dicha construcción sea compatible tanto con tiempos con significado aspectual imperfectivo como con significado aspectual aoristo, si bien en estos casos deben conformar eventos claramente durativos, como en el español actual (García Fernández, 2006, 130-132).

La perífrasis de gradación conclusiva (Fernández de Castro, 1999) o aspectual terminativa (García Fernández, 2006), dejar de + infinitivo, aparece en menos de diez casos en la Carta a sor Filotea de la Cruz: "ni propias reflexas -que he hecho no pocas- han bastado a que deje de seguir este natural impulso que Dios puso en mí” (191-193); “¿qué dejará de hacer y qué dejará de perdonar?" (110); "y así dejé de poner discursos enteros y muchas pruebas que se me ofrecían" (1292-1293). Por último, el aspecto más interesante de esta perífrasis es que es la única, junto a cesar a + infinitivo y parar de + infinitivo, cuya negación supone la afirmación de la realización denotada por la forma no personal: "¿qué pesadumbres no me han dado o cuáles no me han dejado de dar?" (525-526), es decir, 'han seguido dándome'; "con todo no me han dejado de ayudar los muchos [ejemplares] que he leído" (846-847), esto es, 'me han ayudado'.

En cuanto a estar + gerundio, su aparición supera la decena. Se da principalmente en dos tiempos verbales. En presente de indicativo hemos encontrado un caso: "Sin otras que omito, por no trasladar lo que otros han dicho [...], pues en nuestros tiempos está floreciendo la gran Cristina Alejandra, Reina de Suecia, tan docta como valerosa y magnánima” (902-905). En pretérito imperfecto de indicativo aparece en "¿Qué haría, qué movería y qué no haría y qué no movería aquella incomprensible beldad, por cuyo hermoso rostro, como por un terso cristal, se estaban transparentando los rayos de la Divinidad?" (550-553); "de tal manera que de las mismas personas con quienes hablaba, y de lo que me decían, me estaban resaltando mis consideraciones" (750-753); "Si veía una figura, estaba combinando la proporción de sus líneas y midiéndola con el entendimiento y reduciéndola a otras diferentes" (756-758); "Paseábame algunas veces en el testero de un dormitorio nuestro [...] y estaba observando que [...] la vista fingía que sus líneas se inclinaban una a otra” (758-762).

El ejemplo "Estaban en mi presencia dos niñas jugando con un trompo" (777-778) es interesante, pues puede cuestionarse su misma naturaleza perifrástica. Por un lado, el hecho de que haya dos sintagmas, uno de ellos, además, con posible significado locativo, entre el verbo estar y el gerundio permite, sin duda, una posible lectura bastante alejada del prototipo conceptual manejado (Fernández Martín, 2014, 2016a). Pero, por otro lado, al efectuar la prueba de sustitución por así (un adverbio que suele funcionar de forma equivalente al gerundio [Gómez Torrego, 1988; Fernández de Castro, 1999; Yllera, 1999; García Fernández, 2006]), o al eliminar directamente la forma no personal (Olbertz, 1998), la estructura se acerca al prototipo propuesto (§ 1.2): *Estaban en mi presencia dos niñas así con un trompo (prueba de sustitución); ?Estaban en mi presencia dos niñas con un trompo (prueba de omisión). En este caso, entonces, la posibilidad de una interpretación perifrástica no necesariamente prototípica, pero sí aceptable, 
radica en la confluencia de los valores del verbo estar y de los significados de los sintagmas preposicionales que en este contexto concreto son susceptibles de complementarlo.

Además, hemos encontrado algún ejemplo en dos formas no personales. Así, se da en infinitivo en el siguiente paralelismo gramatical: "estar yo leyendo y antojárseles en la celda vecina tocar y cantar; estar yo estudiando y pelear dos criadas [...]; estar yo escribiendo y venir una amiga a visitarme" (449-452). También aparece en gerundio en la oración: "Pues, ¿qué os pudiera contar, Señora, de los secretos naturales que he descubierto estando guisando?" (800801), complementada con la perífrasis poder + infinitivo con valor a caballo entre lo epistémico y lo facultativo (Fernández de Castro, 1999; Fernández Martín, 2015d).

Finalmente, el siguiente fragmento nos ha llamado la atención porque contiene dos ejemplos de la misma perífrasis. En el primero se muestra un contexto prototípico de progresión, de focalización en la duración del hecho en sí mismo de aplaudir. En el segundo, se llama la atención sobre una acción que no tendría, en principio, por qué ser focalizada mediante el gerundio, pues su misma naturaleza eventiva es per se atélica. Y se hace, además, insertando la perífrasis dentro de otra perífrasis como es haber de + infinitivo (Fernández Martín, 2015d), construcción modal con significado a caballo entre una especie de necesidad epistémica que justifica su propio razonamiento y la obligación externa atribuida por la autora del texto a la voluntad de su interlocutor(a): "De donde se conoce la grandeza de vuestra bondad, pues está aplaudiendo vuestra voluntad lo que precisamente ha de estar repugnando vuestro clarísimo entendimiento" (1279-1282).

Por lo que respecta a las perífrasis perfectivas, cabe señalar la ausencia de casos con la continuativa llevar + participio. Solo hemos localizado dos ejemplos de la perífrasis de gradación perfectiva (Fernández de Castro, 1999) o perífrasis aspectual de perfecto resultativo (García Fernández, 2006), esto es, tener + participio.

Creemos que en "Si vos, Señora, gustáredes de que yo haga lo contrario de lo que tenía propuesto, a vuestro juicio y sentir, al menor movimiento de vuestro gusto cederá, como es razón, mi dictamen" (1318-1321) la naturaleza perifrástica se debe a tres motivos esenciales (García Martín, 2002; Fernández Martín, 2016b). Por un lado, el verbo tener, pese a ser un verbo transitivo, carece de complemento directo, toda vez que lo que actúa como complemento directo del participio propuesto. Por otro lado, el participio no cuenta con ningún complemento que pueda acercarlo funcionalmente a un adjetivo, hecho que lo alejaría de su función verbal y acercaría a la construcción, por tanto, al uso meramente predicativo. Asimismo, un tercer motivo para defender que en este caso estamos ante una perífrasis es que cabe fácilmente sustituir la estructura conjunta por haber + participio (lo contrario de lo que [yo] había propuesto), factible, claro está, no solo por la sustitución léxica que se produce entre los verbos tener y haber sobre todo a lo largo de los Siglos de Oro (Girón Alconchel, 2005b; Garachana, 2011a), sino también por la interrelación esencialmente gramatical existente entre ambos ya desde el Medievo. Esto ha permitido que sean las formas con haber las que "han alcanzado un estadio más avanzado que el de las perífrasis verbales, aunque [...] menor que el de las formaciones perifrásticas que formaron los actuales futuro y condicionales simples" (García Fernández, 2006, 160), si bien con tener se ofrece el significado de mantenimiento y duración en el tiempo, fruto del matiz de posesión que en su día tuvo (García Martín, 2002; Girón Alconchel, 2005b; Fernández Martín, 2016b). 
Este tercer motivo es, precisamente, el que pone en tela de juicio la interpretación perifrástica del siguiente ejemplo: "y es menester estar con mucho cuidado y tener escritas en el corazón aquellas palabras del Apóstol” (1363-1365), pues, debido a la impersonalidad del infinitivo, no queda excesivamente claro quién realiza la acción señalada por el participio, lo que implica una doble interpretación de aquellas palabras como complemento directo de tener, en cuyo caso el ejemplo no conformaría perífrasis, o de escribir, en cuyo caso el ejemplo conformaría perífrasis (Yllera, 1999; García Fernández, 2006). La aplicación de las dos pruebas morfosintácticas mencionadas (Olbertz, 1998), esto es, la omisión del participio ("y es menester estar con mucho cuidado y tener en el corazón aquellas palabras del Apóstol”) y su sustitución paradigmática por un adjetivo ("y es menester estar con mucho cuidado y tener listas en el corazón aquellas palabras del Apóstol") o por un sintagma con valor adverbial ("y es menester estar con mucho cuidado y tener \{así/de esta manera\} en el corazón aquellas palabras del Apóstol") contribuye, naturalmente con toda cautela por la diferencia diacrónica, a la interpretación del ejemplo como una estructura disjunta, siempre que se permita asumir una metaforización del significado de posesión de tener.

En resumen, las perífrasis de gradación analizadas no superan en total la cantidad de 25 . No resulta, entonces, llamativo que la más frecuente de este grupo sea estar + gerundio, dada la necesidad de expresar la progresión de las acciones sobre las que la autora pretende llamar la atención.

\subsection{Perífrasis factual de cuantificación}

La única perífrasis que constituye este grupo en la Respuesta es soler + infinitivo, que se da en una amplia variedad de tiempos verbales. Así, su aparición en presente de indicativo y primera persona del singular consta en "Y así, cuando esto considero, acá a mis solas, suelo decir [...]" (57-58) y "Este modo de reparos en todo me sucedía y sucede siempre, sin tener yo arbitrio en ello, que antes me suelo enfadar porque me cansa la cabeza” (771-773). También hay algunos casos en tercera persona, sea del singular, como en "con la inmediación del trato y la comunicación del tiempo, suele hacerse fácil lo que no se pensó ser posible” (1024-1026); sea del plural, como en "Suelen en la eminencia de los templos colocarse por adorno unas figuras de los Vientos y de la Fama" (599-600). Nótese que, en este caso, aunque se interponga un sintagma preposicional entre el verbo auxiliar y el infinitivo auxiliado, la construcción no deja de ser una perífrasis, dado que soler es el único verbo de la lengua española que siempre es auxiliar (Veyrat Rigat, 1993, 153-186).

Asimismo, cabe resaltar el siguiente ejemplo en el que soler + infinitivo incluye otra perífrasis: "Y así, temían que si iba a lo mismo (como las reprensiones, aunque sean tan justas, suelen ser mal reconocidas) corriese peligro su vida” (683-685). En efecto, ser mal reconocidas es una construcción pasiva reconocible gracias a la transitividad del verbo en participio (reconocidas), y dado que el adverbio que lo complementa (mal) lo hace en calidad de complemento de todo el núcleo verbal, no como complemento del adjetivo ( $\$ 2.4$ ).

Por último, también hay una minoría de casos en pretérito imperfecto de indicativo: "Solía sucederme [...]" (478) y "así, me solía ir los ratos que a unas y a otras nos sobraban, a consolarlas 
y recrearme con su conversación" (484-486). Soler + infinitivo es, pues, la única construcción perifrástica que, como se ha dicho, siempre lo es, pues el verbo conjugado nunca aparece como léxicamente pleno.

\subsection{Perífrasis pasivas}

La perífrasis verbal pasiva en español ser + participio (García Fernández, 2006) aparece en el corpus analizado en una docena de casos. Los más frecuentes constan en presente de indicativo ("el que se señala o le señala Dios [...] es recibido como enemigo común" [528-530]), aunque hay alguno también en pretérito indefinido ("Fue arrebatado el Sagrado Vaso de Elección al tercer Cielo [75-76]), pretérito imperfecto de indicativo ("[la esclarecida virgen Eustoquio] por su ciencia era llamada Prodigio del Mundo" [896-897]) e infinitivo ("Veo una sapientísima reina de Sabá, tan docta que se atreve a tentar con enigmas la sabiduría del mayor de los sabios, sin ser por ello reprendida" [851-853]). Sin embargo, los dos ejemplos más llamativos son aquellos en que aparece la forma es debida, fruto de la conversión en voz pasiva del verbo transitivo deber, en estos casos, probablemente, con el significado de "tener obligación de corresponder a alguien en lo moral" (DLE), equivalentes en castellano actual a la impersonal se debe y permitiendo, por el contexto, la aparición del valor modal que contribuye, con su significado léxico, a expresar la obligación externa social (Fernández Martín, 2015d): "os confieso, con la ingenuidad que ante vos es debida [...] que [...]" (129-130) y "Si el estilo, venerable Señora mía, de esta carta, no hubiese sido como a vos es debido, os pido perdón de la casera familiaridad" (1419-1420).

Por su parte, el principal problema de "Pues ¿̇cómo es posible que esto no les arrebatara las almas, que no fuesen enamorados y elevados tras él?" (563-565) se encuentra en la posible doble interpretación de la forma fuesen. Si se trata, sencillamente, del pretérito imperfecto de subjuntivo del verbo ir, defendible por el complemento de desplazamiento tras él, entonces nos encontramos ante una construcción léxica en la que cada participio indica una manera de realizar la acción de ir, es decir, funciona como un complemento predicativo que concuerda en género y número con el sujeto y puede ser sustituido por el adverbio así. Por el contrario, si se entiende como verbo ser, se puede asumir entonces que forma con elevar una perífrasis pasiva, dada la naturaleza transitiva de este verbo y la posibilidad de comprender que al arrebatárseles las almas pudieran efectivamente ser elevados por una fuerza superior que sería Cristo. Con el participio enamorados esta interpretación pasiva puede tener cabida si se lee como transitivo y se entiende que el mismo Dios es quien realiza la acción pasiva de producir el enamoramiento en el sujeto de fuesen (los fariseos, citados líneas más arriba) y se focaliza la acción en el mismo hecho de enamorar.

Cabe aún una tercera interpretación, permitida, tal vez, por la complejidad de la prosa barroca de la escritora. Esta consistiría en entender que en fuesen enamorados tras él se produjera un desplazamiento, es decir, tomando fuesen como pretérito imperfecto de subjuntivo del verbo ir y enamorados como un predicativo. De manera simultánea, se podría considerar que en fuesen elevados (tras él) estuviéramos ante un caso de modificación (Moreno Cabrera, 2003) en voz pasiva en el cual alguien elevaría a los fariseos para que pudieran ir detrás de Cristo. 
Finalmente, en "pues todas no fueron más que mujeres doctas, tenidas y celebradas y también veneradas de la antigüedad por tales" (879-881) resulta interesante la distancia existente entre el verbo ser en pretérito perfecto simple y el primer participio con el que puede formar la perífrasis pasiva (tenidas). En este caso está funcionando como verbo atributivo que une el sujeto (todas) con la atribución (mujeres doctas), a la vez que permite la interpretación perifrástica con tenidas, celebradas y veneradas, difícilmente comprensible solo como atributos, dada la naturaleza transitiva de los tres verbos y la tematización del sujeto paciente frente a la desaparición del agente.

Por lo que respecta a la resultativa estar + participio, ha sido registrada en casi una decena de casos, la inmensa mayoría en tercera persona del singular y del plural del presente de indicativo. En el primer ejemplo que queremos mostrar, la argumentación resulta brillante si se atiende al hecho de que se teme siempre más la constancia de los muchos actos reflexivos de humildad que mantener la paciencia durante un momento que pueda implicar el debido provecho: "Y así, Señora, yo temo más esto que aquello; porque aquello, con sólo un acto sencillo de paciencia, está convertido en provecho; y esto, son menester muchos actos reflexos de humildad y propio conocimiento para que no sea daño" (1373-1377).

Lo interesante de esta perífrasis es que, en algunos casos, permite ilustrar el carácter de la religiosa. Así, en "parece se corresponden y están unidas [las cosas estudiadas] con admirable trabazón y concierto" (416-417) se muestra el valor de una acción realizada cuyo resultado no tiene que ver en absoluto con el agente (que sería la autora, ya que es ella, en definitiva, quien une en su mente "diversas cosas" que estudia [437-438]), puesto que se plantea como un hecho ya consumado, ya dado y, por tanto, imposible de modificar.

El motivo para expresarlo de esta manera, quizá veladamente crítica, se relaciona con la forma en que hace alusión a la consideración social que se tiene de las mujeres como excesivamente ineptas para leer la Biblia: "Y esto es tan justo que no sólo a las mujeres, que por tan ineptas están tenidas, sino a los hombres, que con sólo serlo, piensan que son sabios, se había de prohibir la interpretación de las Sagradas Letras" (926-930). Quizá, como ocurre en algunos ejemplos vistos anteriormente, habría sido más esperable el uso de ser tenido, dado que se entiende que tener por equivale a 'considerar' y, por tanto, la construcción más común tendería a ser en pasiva para acentuar el proceso en sí de dicha consideración. Al emplear la pasiva resultativa, no obstante, se centra la atención lingüística en un hecho asumido como consecuencia de un acto (el de la misma voz activa, esto es, el de tener por), lo que se critica veladamente a la vez que deja sugerir que no todos los hombres, simplemente por serlo, merecen poder acercarse a dicho texto. De ahí la obligación externa social, que promueve con la perífrasis modal haber de + infinitivo (Fernández Martín, 2015d), de prohibir la lectura de las Sagradas Escrituras a todos los que no sean suficientemente cultos para comprenderlas. En una religiosa como sor Juana Inés de la Cruz, emplear esta perífrasis para focalizar el resultado de la acción de escribir las Sagradas Escrituras, como hace en "¿Cómo sin Lógica sabría yo los métodos generales y particulares con que está escrita la Sagrada Escritura?” (317-319) y en "Y también está escrito: Audi, Israel, et tace" (1120), dota al mismo resultado escriturario de un halo místico heredado, hasta cierto punto, de la tradición occidental (Moreno Cabrera, 2005). 
Con estar en forma no personal hemos encontrado dos ejemplos. En el primero, la perífrasis exige un complemento regido introducido por $a$, en lugar de de, muestra de su valor perifrástico en tanto es un argumento del participio, no del verbo estar: "y estar necesitada a que todo sea de mi mano" (1288-1289). El otro ejemplo en infinitivo se encuentra inserto en una perífrasis verbal modal con significado presumiblemente de obligación externa (Fernández Martín, 2015d), pues se muestra el resultado del estado lastimoso como ligado irremediablemente al de estado escarnecido: "y cerebro sabio en el mundo no basta que esté escarnecido, ha de estar también lastimado y maltratado" (637-638). Dicho estado, además, se muestra en presente de subjuntivo por la exigencia del verbo bastar, en la línea de lo exigido en el siguiente ejemplo por parecer, que necesita igualmente el modo subjuntivo y deja a la correlación temporal la obligación del pretérito imperfecto, en que también aparece el dicho parecer: "no me parecía razón que estuviese vestida de cabellos cabeza que estaba tan desnuda de noticias" (266-267).

En efecto, en este ejemplo cabe aludir a la compleja naturaleza de la perífrasis estar + participio cuando a ella se suma la complejidad inherente a la doble naturaleza adjetival y verbal de todo participio, pues en el momento en que este da la mínima muestra de acercarse al polo del adjetivo (por ejemplo, siendo complementado por un adverbio que no puede de ninguna manera complementar a un verbo) se aleja inmediatamente de su categoría verbal o, cuando menos, limita con enormidad las probabilidades de que lo haga. La consecuencia directa es que en esa construcción no se puede hablar de perífrasis resultativa, porque estaríamos entonces ante una estructura meramente atributiva en la que el verbo estar funcionaría como verbo pleno y, por tanto, el adjetivo complementaría su significado sin aportar el matiz semántico de la acción pasiva. Esto es exactamente lo que ocurre, como decimos, en este último ejemplo de sor Juana Inés de la Cruz, en el que se construye una subordinada adverbial consecutiva intensiva introducida por el nexo que a partir del adjetivo desnuda, cuantificado a su vez por tan, lo que implica, como decimos, la práctica imposibilidad de la lectura perifrástica.

Estamos, por tanto, ante apenas una veintena de ejemplos que expresan la voz pasiva del español, tanto en su visión de la acción como un todo (con ser), como en su percepción del resultado denotado por el participio (con estar). El hecho de que los ejemplos con las construcciones $\{$ ser/estar $\}$ + participio sean menos frecuentes que en otros géneros discursivos, y de que ambas estructuras estén más igualadas cuantitativamente que en otros estadios de la lengua, permite asistir a la disminución de su uso a finales del siglo XVII, acercándolo lentamente al del español actual.

\section{INTERPRETACIÓN DE LOS DATOS}

La mayoría de las construcciones estudiadas con verbos de movimiento se encuentran en la fase de semiperífrasis, como corresponde al español de finales del siglo XVII, que continúa, por tanto, una línea ya empezada en el Medievo, según atestigua Zieliński (2014) y se confirma en los siglos posteriores (Fernández Martín, 2015a, 2016c, 2019). En estos también se observa que la cantidad de semiperífrasis superfluas es la más frecuente de todas las perífrasis formadas con verbos de movimiento, seguidas de las semiperífrasis fuertes y de las semiperífrasis en potencia. Diferentes son, claro está, las construcciones altamente gramaticalizadas, pues, a diferencia de los textos decimonónicos en que se constatan un par de casos (Fernández Martín, 2016c), en el 
de la Respuesta no encontramos ninguno, tal vez porque aún no se ha producido la modalización que afectará posteriormente a los verbos de movimiento (Melis, 2005; Garachana, 2011b). Esto implica, a nuestro juicio, que el cambio lingüístico que sufre la perífrasis verbal es especialmente lento, hasta el punto de que se mantienen durante mucho tiempo las proporciones en las dos fases centrales, quizá debido a la convivencia con los usos no perifrásticos (semiperífrasis en potencia) de los verbos de movimiento (Fernández Martín, 2018).

Precisamente esta convivencia, en lo que respecta a los verbos copulativos por excelencia del español, es la que caracteriza la aparición de la voz pasiva en el texto, tanto desde la acción (con ser) como desde el resultado (con estar). El hecho de que ambas construcciones estén cuantitativamente muy igualadas hace pensar en que a finales del siglo XVII se encuentran en un momento de equilibrio funcional, en el que los distintos factores que interactúan a la hora de construir sus significados perifrásticos (pasivos) o no perifrásticos (atributivos) siguen prácticamente las mismas restricciones semántico-sintácticas que en la actualidad, que son, en esencia, el aspecto léxico de los participios que los acompañan (más bien verbales, más bien adjetivales) y el aspecto gramatical del verbo auxiliar. La diferencia, por supuesto, radica en que en el español áureo la reestructuración de la interrelación entre haber y tener estaba directamente relacionada con la de los verbos ser y estar, pues todavía competían por convertirse en verbos auxiliares (Fernández Martín, 2016b, 2016d). El español de sor Juana, a nuestro juicio, ya es plenamente actual en este sentido, pues no hemos registrado ningún caso en que tener + participio o ser + participio funcionen como tiempos compuestos, esto es, en el primer caso, con el participio invariable, y en el segundo, con verbos intransitivos, como se dio hasta finales del siglo XVI (Keniston, 1937, §§ 33.8, 33.9; Yllera, 1980; Fernández Martín, 2016b, 2016d).

En otras palabras, la posibilidad de que los mismos verbos puedan conformar una perífrasis en unos contextos y una construcción plena en otros, dependiendo, precisamente, de dichas restricciones, forma parte de la esencia misma de la perífrasis verbal, en ese doble juego - ya registrado en la bibliografía (Veyrat Rigat, 1993, 1997; Yllera, 1999; Gómez Torrego, 1999; Zieliński, 2014) - de encontrarse entre la función auxiliar (gramática) y la función plena (léxico). Por este motivo, puede discutirse la naturaleza perifrástica de la voz pasiva en español actual, pero no puede hacerse desde una perspectiva diacrónica, pues las construcciones \{ser/estar\} + participio se comportan, en la interrelación auxiliar-pleno y en su expresión aspectual dentro del sistema gramatical, como las demás perífrasis (Yllera, 1980; Veyrat Rigat, 1993, 1997; Fernández Martín, 2015a, 2016d).

En cuanto a las perífrasis de gradación y cuantificación, el hecho de que las más frecuentes sean soler + infinitivo y estar + gerundio, seguidas de dejar + gerundio y de empezar a + infinitivo, nos hace pensar en la importancia de explicitar la frecuencia de la realización de la acción unida a su progresión, pero sobrepuesta a su detención, si bien resaltar esta es más relevante, cuantitativamente, que focalizar su comienzo. A nuestro juicio, a la autora le interesa más detenerse en la progresión de ciertas acciones mediante un gerundio (lo que contrasta con las perífrasis con verbos de movimiento, donde son mucho más frecuentes las que se forman con infinitivo) que en su comienzo o en su final, lo que implica una posible intención de focalizar el hecho de que resulte siempre más costoso el mantenimiento progresivo de la acción que interrumpirla (dejar de + infinitivo) o comenzarla (empezar a + infinitivo). 
Desde una perspectiva cualitativa, se observa en las perífrasis analizadas solo una parte de los valores esperables para la época. Así, el significado más claro en la perífrasis ir $a+$ infinitivo es el temporal (tanto futuro inminente como próximo), que se relaciona directamente con el significado intencional, mientras que de los valores de ruego o mandato y acción inminente frustrado no hemos registrado ejemplos.

De forma similar, el valor más común, ya constatado, de $i r$ + gerundio es el progresivo, si bien hay algún caso con significado descriptivo ("como voy tratando de mis impugnadores" [1194-1195]). No hemos encontrado el valor incoativo-progresivo ni el durativo-distributivo, probablemente porque estos valores son expresados, como hemos visto en la sección anterior, por las perífrasis ponerse $a+$ infinitivo, empezar $a+$ infinitivo y llegar $a+$ infinitivo.

Por último, la perífrasis volver $a+$ infinitivo (que ya no aparece en ningún ejemplo como tornar $a+$ infinitivo, como corresponde a finales del siglo XVII) muestra los dos valores esenciales de iteración y restauración. No la hemos detectado con el significado de incoatividad que se registra desde la Edad Media (Yllera, 1980; Keniston, 1937).

Las posibles diferencias con respecto a un texto tipológicamente narrativo, como el que, supuestamente, cabría esperar en una autobiografía, podrían explicarse porque en realidad el texto de la Respuesta está conformado por tipos textuales más cercanos a lo expositivoargumentativo que a lo narrativo-descriptivo. En este caso, estaríamos ante un tipo de texto de características más bien ensayísticas (filosófico-teológicas) camuflado en una autobiografía enviada por medio de una epístola: la alta frecuencia de soler + infinitivo encaja con la expresión de los hábitos en el pasado, pero la gran cantidad de perífrasis que acentúan la gradación de la acción (empezar a + infinitivo, dejar de + infinitivo, estar + gerundio), su realización desde el sujeto agente (ser/estar + participio), su intención (ir $a+$ infinitivo) y su repetición (volver $a+$ infinitivo) dejan entrever, según se contemplan de forma sucesiva en conjunto, una progresión en el razonamiento de tipo deductivo que emplea la escritora para defenderse de las críticas esbozadas en la Carta.

De ser así, esto implicaría, entonces, que el género autobiográfico se muestra como un continente formal en el que sor Juana Inés de la Cruz desea introducir un contenido teológico vetado a las mujeres en la época. El género discursivo de la autobiografía servía para controlar a las religiosas y, a la vez, valorar el posible "peligro" de sus experiencias místicas. Sor Juana Inés de la Cruz da una vuelta de tuerca a este (meta)discurso, al ser capaz de utilizarlo para escribir una defensa feminista del cristianismo dentro de la visión masculina del mundo: desde la perspectiva estructural, solo podría aceptarse en ella un género textual típicamente femenino, esto es, una autobiografía en formato de carta; desde la perspectiva del contenido, solo podría defender su vida y, con ella, su auténtico quehacer literario en el terreno propio del varón por encima del cual, en el Siglo de Oro (como ella muy bien sabía), solo se encontraba Dios.

\section{CONCLUSIONES}

Como se ha visto, la mayoría de las construcciones estudiadas con verbos de movimiento se encuentran en la fase de semiperífrasis superflua, lo que no debe resultar excesivamente sorprendente para finales de siglo XVII, especialmente si se tiene en cuenta la evolución de estas 
perífrasis desde la Edad Media. Esta tendencia encaja, a su vez, con un factor que creemos esencial en el caso de las perífrasis verbales, como es el hecho de que siempre (es decir, en todas las fases de la historia de la lengua) se encuentran entre la gramática y el léxico.

En efecto, esta constante interacción de las construcciones que nos ocupan entre la morfosintaxis y el lexicón forma parte de la naturaleza gradual de las perífrasis en prácticamente todos los estadios de la lengua, entendiendo que la perspectiva diacrónica, tomada de forma holística y macroestructural, permite contemplar los distintos grados de gramaticalización como un todo. Esto implica, por un lado, que toda perífrasis verbal va a beber siempre del léxico, al ofrecer valores semánticos claros, especialmente, en su auxiliado; y de la gramática, al mostrar significados funcionales en su auxiliar que en otras lenguas son expresados por morfemas, como el temporal, el aspectual o incluso el modal. Por otro lado, esto supone que cuando la perífrasis en cuestión se acerca demasiado a uno de los dos polos del continuo (gramática o léxico) deja de ser perífrasis stricto sensu para pasar a pertenecer a otra categoría gramatical (locución, marcador discursivo, tiempo verbal), aunque histórica y holísticamente nunca haya dejado de ser una perífrasis (Fernández Martín, 2018). En cuanto a las perífrasis que expresan valores pasivos, se dan en la Respuesta en un equilibrio funcional bastante similar al del español del siglo XXI, igual que ocurre, grosso modo, con las perífrasis de gradación y cuantificación, las cuales, sin embargo, no ofrecen en dicho texto todos los valores que se han registrado en otros documentos de la misma época.

A partir de estos datos, se ofrecen, en definitiva, dos aportaciones esenciales. Por un lado, se insiste en la necesidad de tratar a cada grupo de perífrasis de una forma distinta, pues su funcionamiento histórico, aunque similar, no es en ocasiones comparable. De ahí que hayamos establecido unos grados de gramaticalización para las construcciones con verbos de movimiento que no coinciden, naturalmente, con los valores de las perífrasis que expresan gradación, cuantificación o pasividad. Quizá en un futuro próximo podría ocurrir, incluso, que fuera necesario (y metodológicamente útil) hablar de distintos procesos interrelacionados con el más general de gramaticalización (metaforización, lexicalización, pragmatización...) para explicar en qué medida afecta cada cuál a qué grupo de perífrasis, realizando, tal vez, algún tipo de escisión entre ellos para ajustarse de forma más rigurosa a lo que ocurre en la realidad de cada fenómeno.

Por otro lado, consideramos imprescindible incorporar al análisis lingüístico los textos escritos por mujeres a lo largo de la historia. No solo pueden contribuir, como productoras de lengua, a profundizar más en el conocimiento histórico del idioma, por aportar matices o significaciones que hayan podido pasar desapercibidos en textos analizados hasta la fecha, sino que también pueden ser esenciales para ayudar a comprender de una forma más efectiva las interacciones sociales que se ocultan tras el cambio lingüístico.

Conviene, finalmente, recordar que lo que se pretende con este trabajo es estudiar el funcionamiento de las perífrasis verbales con valor factual en la Respuesta a sor Filotea de la Cruz. Se ha propuesto el análisis de un objeto lingüístico muy concreto, en un texto igualmente definido, como punto de partida para futuros estudios que permitan contrastar lo indicado aquí con otros fenómenos lingüísticos similarmente (o no) concretos en textos igualmente (o no) definidos. De momento, no hay muchas más opciones si se desea acceder al habla real de las mujeres hispanohablantes en determinado período (y espacio) de nuestra historia y, por tanto, 
no hay muchas maneras más de establecer comparaciones que se sustenten por sí mismas en futuros trabajos, si no es empezando por el análisis minucioso de las estructuras lingüísticas (en este caso, las perífrasis verbales) que componen los distintos discursos. En términos absolutos, no hemos pretendido dar a entender que un simple idiolecto (reducido aquí a un texto que, evidentemente, solo es una muestra representativa) pueda emplearse para generalizar sobre el estudio de la lengua, pero sí que, si no hay más remedio que operar metodológicamente de este modo, es lícito hacerlo, por un lado, por la desigualdad cuantitativa entre textos masculinos y textos femeninos codificados en los corpus (o, en general, editados) y, por otro, porque así lo permite la regla de inferencia de introducción del cuantificador universal de la lógica clásica de predicados. Se ha buscado, pues, tanto hacer reflexionar sobre la necesidad de incorporar textos escritos por mujeres al análisis histórico del español, de donde han sido excluidas durante bastante tiempo, como contribuir a cumplir dicha necesidad con un comienzo muy concreto (y muy modesto), como es el presente análisis del funcionamiento de determinadas construcciones en un único texto. Todo ello no es óbice, en cualquier caso, para defender que las estructuras morfosintácticas analizadas, tomadas con la cautela que debe tener todo estudio cualitativo, dan pie a interpretar que el texto de sor Juana Inés de la Cruz ofrece un continente estructural con forma de epístola autobiográfica para abarcar el contenido, que puede considerarse un tratado filosófico-teológico sobre el derecho de la mujer a participar (a su modo) del cristianismo.

\section{NOTAS}

1 Esta escasa atención prestada a los textos escritos por mujeres se relaciona, naturalmente, con la igualmente escasa atención prestada a la edición de textos escritos por mujeres. Si hay pocas publicaciones que recojan los productos textuales de las féminas a lo largo de la historia de la lengua española (limitados, a su vez, por cuestiones sociopolíticas solo comprensibles desde que se mantiene cierta perspectiva de género), parece lógico que también haya pocos estudios centrados en analizar su quehacer lingüístico. A modo meramente anecdótico, en el II Congreso Internacional de Morfosintaxis Histórica Hispanoamericana celebrado en la Facultad de Filología de la Universidad de Sevilla en noviembre de 2018, la profesora Concepción Company, a quien agradezco enormemente las aclaraciones posteriores a título individual, expuso en público que tan solo el $20 \%$ de los textos del Corpus Diacrónico y Diatópico del Español de América (cordiam.org), que ella misma dirige, estaban escritos por mujeres.

2 Recuérdese la equivalencia que hace Sapir, en lo referente a la forma lingüística, entre Platón y un porquerizo macedonio, por un lado, y Confucio y un salvaje cazador de cabezas de Assam, por otro.

\section{REFERENCIAS BIBLIOGRÁFICAS}

ALMEIDA CABREJAS, B., DÍAZ MORENO, R., y FERNÁNDEZ LÓPEZ, M. C. 2017. "Cansada tendré a vuestra Excelencia con tan larga carta". Estudios sobre aprendizaje y práctica de la escritura por mujeres en el ámbito hispánico (150o-190o). Lugo: Axac.

BARRA-JOVER, M. 2012. "Método y teoría del cambio lingüístico: argumentos en favor de un 'método idiolectal”, en Bastardín Candón, T. y Rivas Zancarrón, M. (coords.), Actas del IX 
Congreso Internacional de Historia de la Lengua Española. Madrid/Frankfurt: Iberoamericana/ Vervuert, pp. 263-292.

BRESCIA, P. A. J. 1998. “El ‘crimen’ y el castigo: la Carta Atenagórica, de Sor Juana Inés de la Cruz”, Caravelle, 70(1), pp. 73-96.

DEAÑO, A. 2009. Introducción a la lógica formal. Madrid: Alianza.

DE LA CRUZ, SOR JUANA INÉS. 1994. Obra selecta. Tomo II. Glantz, M. y Bravo Arriaga, M. D. (eds.). Caracas: Biblioteca Ayacucho.

FERNÁNDEZ DE CASTRO, F. 1999. Las perífrasis verbales en el español actual. Gredos: Madrid.

FERNÁNDEZ MARTÍN, P. 2014. "Cuestiones metodológicas en el estudio de las perífrasis verbales: interrelaciones entre sintaxis, semántica y pragmática”, en Girón Alconchel, J. L. y Sáez Rivera, D. M. (eds.), Procesos de gramaticalización en la historia del español. Madrid/Frankfurt: Iberoamericana/Vervuert, pp. 119-158.

FERNÁNDEZ MARTÍN, P. 2015a. "Lo que Sancho vino a decir y después tornó a creer: un estudio diacrónico de perífrasis con verbos de movimiento en Don Quijote de la Mancha”, Lingüística y literatura, 67, pp. 141-162.

FERNÁNDEZ MARTÍN, P. 2015b. “¿Dónde vas a parar, Sancho?: gramaticalización, lexicalización y pragmatización”, Dirāsāt Hispānicas, 2, pp. 87-108.

FERNÁNDEZ MARTÍN, P. 2015c. "Algunas perífrasis verbales de gerundio en el español de los Siglos de Oro: prototipo conceptual, esquema de sucesos y géneros discursivos”, Revista de Historia de la Lengua Española, 10, pp. 37-76.

FERNÁNDEZ MARTÍN, P. 2015d. "Perífrasis verbales con valor deóntico en el discurso epistolar de santa Teresa de Jesús”, en Pérez Cuenca, I., Abradelo de Usera, M. I., y Cid Vázquez, T. (coords.), Actas del Congreso Interuniversitario Santa Teresa de Jesús, Maestra de Vida. Ávila: Servicio de Publicaciones, Universidad Católica de Ávila, pp. 1257-1277.

FERNÁNDEZ MARTÍN, P. 2016a. "La terminología metalingüística: el concepto de perífrasis verbal en el español de los Siglos de Oro”, Debate Terminológico, 15, pp. 2-31.

FERNÁNDEZ MARTÍN, P. 2016b. " $\{$ Tener/llevar $\}$ + participio en el castellano de los Siglos de Oro y algunas notas interlingüísticas”, Revista de Filoloxía Asturiana, 16, pp. 87-115.

FERNÁNDEZ MARTÍN, P. 2016c. "Ir, venir, volver... Clarín: cinco perífrasis verbales con verbos de movimiento en trece de los cuentos de Leopoldo Alas", Anuario 2016. Instituto de Estudios Zamoranos Florián de Ocampo, 31, pp. 361-411.

FERNÁNDEZ MARTÍN, P. 2016d. "\{Ser/estar\} + participio en el español áureo (siglos XVI y XVII): perspectiva diacrónica de una oposición aspectual”, Épilogos, 5, Temps, mode et aspect en espagnol. Rouen: Publications Électroniques de l'ERIAC, pp. 21-74.

FERNÁNDEZ MARTÍN, P. 2018. “¿Qué tiene que ver esto con estotro? Diversos senderos de evolución de tres categorías lingüísticas”, en Girón Alconchel, J. L., Herrero Ruiz de Loizaga, F. J., y Sáez Rivera, D. M. (eds.), Procesos de textualización y gramaticalización en la historia del español. Madrid/Frankfurt: Iberoamericana/Vervuert, pp. 135-187.

FERNÁNDEZ MARTÍN, P. 2019. Las perífrasis verbales del español: una perspectiva histórica. Madrid: Arco/Libros.

GARACHANA, M. 2010. "Gramática y pragmática en la evolución de la perífrasis verbal. El caso de venir + $a+$ infinitivo”, Español Actual, 92, pp. 69-101. 
GARACHANA, M. 2011a. "Perífrasis sinónimas. ¿Gramaticalizaciones idénticas? Más retos para la teoría de la gramaticalización”, en De Bustos Tovar, J. J., Cano Aguilar, R., Méndez García de Paredes, E., y López Serena, A. (coords.), Sintaxis y análisis del discurso hablado en español. Homenaje a Antonio Narbona. Vol. 2. Sevilla: Secretariado de Publicaciones de la Universidad de Sevilla, pp. 779-798.

GARACHANA, M. 2011b. "Del espacio al tiempo en el sistema verbal del español. Las perífrasis verbales ir $+a+$ infinitivo, venir $+a+$ infinitivo y volver $+a+$ infinitivo", en Carsten Sinner, C., Ramírez Luengo, J. L., y Torrens Álvarez, M. J. (coords.), Tiempo, espacio y relaciones espaciotemporales desde la perspectiva de la lingüística histórica. San Millán de la Cogolla: Cilengua, pp. 89-124.

GARCÍA FERNÁNDEZ, L. (dir.). 2006. Diccionario de perífrasis verbales. Madrid: Gredos.

GARCÍA MARTÍN, J. M. 2002. La formación de los tiempos compuestos del verbo en español medieval y clásico. Aspectos fonológicos, morfológicos y sintácticos. Anejo XLVII de Cuadernos de Filología. Valencia: Universitat de València.

GARCÍA-PAGE SÁNCHEZ, M. 2008. Introducción a la fraseología española. Estudio de las locuciones. Barcelona: Anthropos.

GIRÓN ALCONCHEL, J. L. 2004. "Gramaticalización y estado latente”, Dicenda. Cuadernos de Filología Hispánica, 22, pp. 71-88.

GIRÓN ALCONCHEL, J. L. 2005a. "Gramaticalización y gramatización. Los futuros analíticos”, en Santos Ríos, L. et al. (eds.), Palabras, norma, discurso. En memoria de Lázaro Carreter. Salamanca: Ediciones Universidad de Salamanca, pp. 581-592.

GIRÓN ALCONCHEL, J. L. 2005b. “Cambios gramaticales en los Siglos de Oro”, en Cano, R. (coord.), Historia de la lengua española. Barcelona: Ariel, pp. 859-894.

GIRÓN ALCONCHEL, J. L. 2007. "Lexicalización y gramaticalización en la creación de marcadores del discurso... y de otras palabras”, en Stark E., Schmidt-Riese, R., y Stoll, E. (eds.), Romanische Syntax im Wandel. Tübingen: Narr Francke, pp. 363-385.

GÓMEZ MANZANO, P. 1992. Perífrasis verbales con infinitivo (valores y usos en la lengua hablada). Madrid: UNED.

GÓMEZ TORREGO, L. 1988. Perífrasis verbales. Sintaxis, semántica y estilística. Madrid: Arco/Libros.

GÓMEZ TORREGO, L. 1999. "Los verbos auxiliares. Las perífrasis verbales de infinitivo", en Bosque, I. y Demonte, V. (coords.), Gramática descriptiva de la lengua española 2. Las construcciones sintácticas fundamentales. Relaciones temporales, aspectuales y modales. Madrid: Espasa, pp. 3323-3389.

HEINE, B. 1992. "Grammaticalization chains", Studies in Language, 16(2), pp. 335-368.

HEINE, B. 2003. "Grammaticalization" en Joseph, B. D. y Janda, R. D. (eds.), The handbook of historical linguistics. Oxford: Blackwell, pp. 575-599.

IGLESIAS BANGO, M. 1988. "Sobre perífrasis verbales", Contextos, VI(12), pp. 75-112.

KENISTON, H. 1937. The syntax of Castilian Prose. The sixteenth century. Chicago: Chicago University Press.

KNOWLTON, E. C. 1981. "Un problema textual de la Respuesta a Sor Filotea de la Cruz", Anuario de Letras. Lingüística y filología, 19, pp. 327-333. 
MELIS, C. 2006. "Verbos de movimiento. La formación de los futuros perifrásticos", en Company Company, C. (dir.), Sintaxis histórica de la lengua española. Primera parte: La frase verbal. México: Universidad Nacional Autónoma de México / Fondo de Cultura Económica, pp. 875-970.

MORENO CABRERA, J. C. 2003. Semántica y gramática. Sucesos, papeles semánticos y relaciones sintácticas. Madrid: Antonio Machado.

MORENO CABRERA, J. C. 2005. Las lenguas y sus escrituras. Madrid: Síntesis.

OLBERTZ, H. 1998. Verbal periphrases in a functional grammar of Spanish. Berlín: Mouton de Gruyter.

POOT HERRERA, S. 2008. "Sor Juana Inés de la Cruz en su Respuesta: 'Entreme religiosa [...] porque para la total negación que tenía al matrimonio [...] era lo más decente que podía elegir", en Zugasti, M. (ed.), Sor María de Jesús de Ágreda y la literatura conventual femenina en el Siglo de Oro. Soria: Cátedra Internacional Alfonso VIII, pp. 151-168.

REAL ACADEMIA ESPAÑOLA. 2001. Diccionario de la lengua española. Disponible en https://dle.rae.es.

ROMANI, P. 2006. "Tiempos de formación romance I. Los tiempos compuestos", en Company Company, C. (dir.), Sintaxis histórica de la lengua española. Primera parte: La frase verbal. México: Universidad Nacional Autónoma de México / Fondo de Cultura Económica, pp. 241-346.

SALAZAR MALLÉN, R. 1978. Apuntes para una biografía de sor Juana Inés de la Cruz. México: Universidad Nacional Autónoma de México.

SAPIR, E. 1954. El lenguaje. Introducción al estudio del habla. México: Fondo de Cultura Económica.

VEYRAT RIGAT, M. 1993. Aspecto, perífrasis y auxiliación: un enfoque perceptivo. Valencia: Universitat de València.

YLLERA, A. 1980. Sintaxis histórica del verbo español: las perífrasis medievales. Zaragoza: Universidad de Zaragoza.

YLLERA, A. 1999. "Las perífrasis verbales de gerundio y participio", en Bosque, I. y Demonte, V. (coords.), Gramática descriptiva de la lengua española 2. Las construcciones sintácticas fundamentales. Relaciones temporales, aspectuales y modales. Madrid: Espasa, pp. 3392-3439.

ZIELIŃSKI, A. 2014. Las perífrasis de los verbos de movimiento en español medieval y clásico. Cracovia: Wydawnictwo Universytetu Jagiellońskiego.

\section{*AGRADECIMIENTOS}

Este trabajo se enmarca dentro del Proyecto I+D del Ministerio de Economía y Competitividad titulado "Procesos de gramaticalización en la historia del español (V): gramaticalización, lexicalización y análisis del discurso desde una perspectiva histórica” (FFI2015-64080), dirigido por el Dr. Francisco Javier Herrero Ruiz de Loizaga, de la Universidad Complutense de Madrid.

\section{NOTA SOBRE LA AUTORA}

Patricia Fernández Martín es doctora en Lengua Española y profesora en la Universidad Autónoma de Madrid, España. ORCID: 0000-0003-4112-5507 